\title{
Cushing's syndrome caused by an occult source: difficulties in diagnosis and management
}

Ashley B Grossman, Philip Kelly, Andrea Rockall, Satya Bhattacharya, Ann McNicol and Tara Balwick Nature Clinical Practice Endocrinology \& Metabolism (2006) 2: 642-647 [doi:10.1038/ncpendmet0327]

doi:10.1038/ncpendmet0387 CORRIGENDUM

In the November 2006 issue, the surname of the final author was published as 'Balwick'.

This should have appeared as 'Barwick'.

\section{Don't miss the following articles that will soon be appearing in the pages of Nature Clinical Practice Endocrinology \& Metabolism:}

\section{VIEWPOINT}

Measure for measure-sugar or fats? Reconciling cardiovascular and diabetes risk with niacin therapy Robert S Rosenson

\section{PRACTICE POINTS}

What factors determine patient adherence to osteoporosis treatment regimens?

René Rizzoli

Is long-term glucocorticoid therapy associated with a high prevalence of asymptomatic vertebral fractures in postmenopausal women?

Robert S Weinstein

\section{REVIEWS}

Pheochromocytoma: recommendations for clinical practice from the First International Symposium

Karel Pacak, Graeme Eisenhofer, Håkan Ahlman, Stefan R Bornstein, Anne-Paule Gimenez-Roqueplo,

Ashley B Grossman, Noriko Kimura, Massimo Mannelli, Anne Marie McNicol and Arthur S Tischler

Drug Insight: mechanisms of action and therapeutic applications for agonists of peroxisome proliferative activated receptors

Philippe Gervois, Jean-Charles Fruchart and Bart Staels

\section{CASE STUDY}

Recurring adrenal carcinoma after laparoscopic resection

Angelika Schlamp, Klaus Hallfeldt, Ullrich Mueller-Lisse, Thomas Pfluger and Martin Reincke

Please note that the title details are not finalized and might be subject to change. 